\title{
Review Article \\ Robert H. Goetz: A Heritage of Coronary Artery Bypass Surgery
}

\author{
Md. Anisuzzaman ${ }^{1}$, Nazmul Hossain ${ }^{2}$
}

\begin{abstract}
:
Robert H. Goetz performed the first successful clinical coronary artery bypass operation on May 2, 1960. He used a nonsuture technique to connect the right internal mammary artery to the coronary artery by means of a modified Payr's cannula made of tantalum. The patency of the anastomosis was demonstrated angiographically
\end{abstract}

and the patient remained free of angina pectoris for 1 year. It was an important and brave step forward, a step that was far ahead of its time. But unfortunately, his pioneering work was not appreciated properly.

Keywords: Coronary artery; Heritage bypass surgery

\section{Introduction:}

Coronary artery bypass operation is one of the most significant surgical achievements of the $20^{\text {th }}$ century. Many surgeons put their efforts for successful implementation of the procedure. The names of Carrel, Vineberg, Kolesov, Favaloro, DeBakey are well known for their contribution. But, Robert H. Goetz, Professor of surgery at the Albert Einstein college of Medicine (Bronx, New York) who performed the world first successful coronary artery bypass surgery. ${ }^{11}$ Only few know this fact, and even fewer know the fascinating biography of life of Dr. Goetz. ${ }^{1}$

\section{Early history to improve myocardial blood supply:}

On May 5, 1910, Alexis Carrel described the first attempt of coronary artery bypass in dog using a segment of the carotid artery. ${ }^{14}$ Carrel's attempt was to be fulfilled first by Demikhov in experiment and then by Goetz in clinic. In 1945, Arthur Vineberg first used internal thoracic artery as a conduit in experiment and implanted directly into myocardium to improve myocardial perfusion. ${ }^{9,13}$

In the beginning of the 1950s many surgeons attempted experimentally to anastomose ITA to the coronary artery

1. Asst. Prof. Cardiac Surgery, Chittagong Medical College, Bangladesh.

2. Assoc. Prof. Cardiac Surgery, Chittagong Medical College, Bangladesh.

Address of Correspondence: Dr. Md Anisuzzaman, Assistant Professor, Department of Cardiac Surgery Chittagong Medical College. Mobile: 01717180057, E-mail: aniscts10@gmail.com and success was achieved simultaneously and independently by Vladimir Demikhov in Russia ${ }^{10}$ and Gordon Murray in Canada. ${ }^{12}$

On July 29,1953, Demikhov performed the first successful coronary artery bypass with Payr's cannula. Four dogs survived more than 2 years and patency was demonstrated in each. ${ }^{8}$ However, Goetz was not aware of Demikhov's work.

In late 1950s Dr. Goetz begin his experiments and it was encouraging. Then he determined to perform the first successful coronary bypass operation in a patient. It is interesting to describe the journey of Dr. Goetz life that prepared him for this success. ${ }^{11}$

\section{Journey of Dr. Goetz:}

Robert Hans Goetz was born in Frankfurt on April 17, 1910, into the family of sculptor Johan Konrad Goetz and his wife Emilie. He spent the years of the first world war with his grandparents in a small village in the black forest, the school of which consisted of one room and a teacher for all grades. He easily passed an examination and was accepted to Helmholtz Ober real Schule upon his return to Frankfurt after the war. After matriculation in 1929, he started to study medicine at the university of Frankfurt and got highest grade in first semester. In the second semester under Dr Albrecht Bethe, Professor of 
physiology, studying the peripheral circulation using arm plethysmograph (Fig 1). Goetz struggled sometimes with the device then come up with a better device- a digital plethysmograph with optical recording. And with this device he could accurately record changes of peripheral blood flow with each heartbeat. Still a student he published the method, at the urging of Professor Bethe, in the Klinische Wochenschrift, one of the most prestigious German medical journal in 1935, the article was accepted as his thesis for his MD degree. Though Goetz passed the MD exam, he did not get his medical diploma because the Nazi minister of the interior declared him politically unreliable. The diploma was issued to Goetz in 1997, exactly 62 years later.

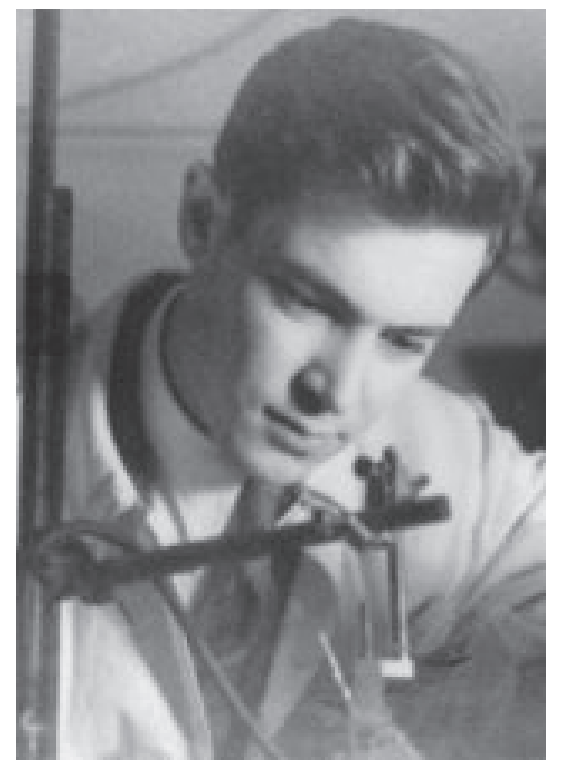

Fig.-1: Robert H. Goetz in Bethe's laboratory in 1932.

At the end of 1933, his dream of studying medicine came to an abrupt end. The Nazi bosses took over by means of decrees and regulations, all intended to make it impossible for Jews and other undesirables to continue to study medicine. At that time all the students were forced to join the National Socialist Student Organization. In September 1934, Goetz passed the final examination. The first he did was to resign from NS student Organization. And then the minister of the interior declared him politically unreliable and refused to grant him both medical license and medical diploma. He felt that it was better for him to get out of Germany and left for Switzerland with ten marks in pocket and no papers to show that he was a qualified physician. Luckily his former Professor Dr. Hans Bluntschli, who had been thrown out of Germany by Nazis, knew him and gave him a job as assistant in his department and working there to study placental circulation. The results of this study were accepted for thesis for the MD degree. When his research found its way into the 1936 edition of Starling's Textbook of Physiology, it opened the door to join the Department of Physiology at the Edinburgh University for one year. And joined at Professor De Burg-Daly's department in Edinburgh and began investigations into the control of the circulation of the intestine. As the year in Edinburgh was coming to an end, he saw just by chance on the blackboard at the dean's office an advertisement by the University of Cape Town, South Africa offering a research fellowship in the department of surgery. And his application was accepted and joined in October 1937. In 1938, Groote Schuur hospital was opened. By 1940, Goetz got a vascular laboratory there. Goetz did not have access to the patients. The South African Medical Council did not recognize his German or Swiss degree. In 1944, he passed the exam (MB, ChB, Cape Town) and finally become licensed physician. By 1945, Dr Goetz received a fully blown Unit of Vascular Diseases. When South Africa joined the WW-II at the side of England, Goetz suddenly became an enemy alien and his movements were severely restricted and he had to report regularly to police. In the meantime, Cape Town appointed him Associate professor of surgical Research, got his own department and unit for Vascular Diseases at Groote Schuur Hospital.

In 1940s, there was an intense interest in the cause of hypertension. Goetz studied the physiology of giraffe and his team undertook two expeditions in 1954 and 1956. The result was presented at the International Congress of Physiology in Brussels, earned the Vesalius medal. ${ }^{4}$

In 1950s, Goetz become an internationally recognized authority in the field of circulation. His various studies were published in the British Journal of surgery, the American Heart Journal, and The Lancet. Goetz lectured extensively and his contributions to the field were diverse, from Raynaud's phenomenon to heart transplantation. By 1945, Goetz seen unusual number of Raynaud's phenomenon with scleroderma with visceral lesions not reported in the literature. The heart, the lungs, intestine, kidneys were all affected. It was in the Goetz laboratory that Lionel Opie worked up the pulmonary changes in progressive systemic sclerosis(PSS) with special reference to pulmonary hypertension. Dr Opie's paper own the top prize in a competition organized by the American College of Chest Physicians and earned him a trip to Oxford that started him on his scientific career. ${ }^{4}$ After Goetz's appointment in Groot Schuur Hospital, he established Peripheral Vascular Clinic there in 1946. The 
whole world knows the name of Christiaan Barnard (Fig 2), who performed the first human heart transplantation at Groot Schuur Hospital in 1967 and became the world's hero overnight. Yet, only few know Goetz, a man who worked hard to bring academic surgery at Groot Schuur hospital up to the highest possible level. However, it was Goetz's work on coronary artery bypass surgery that assured immortality for his name (Fig 3).

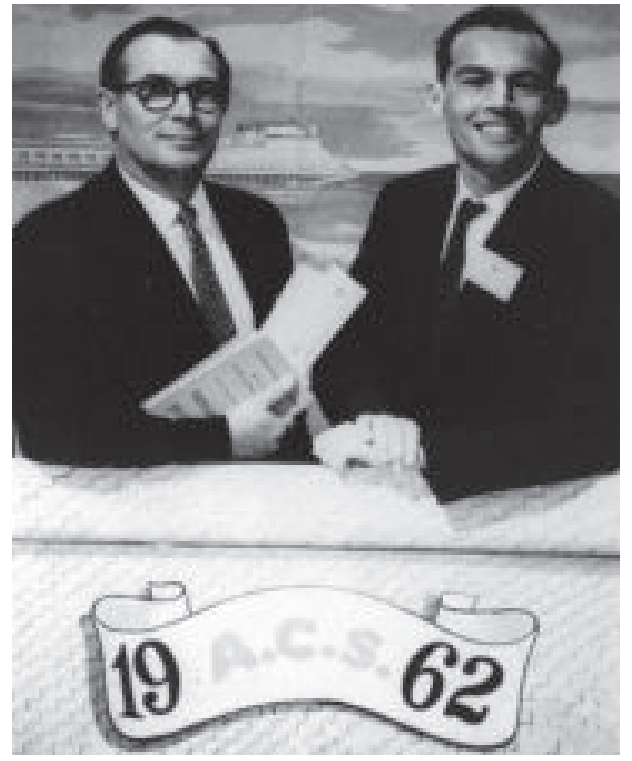

Fig.-2: Robert H. Goetz and Christiaan Barnard in 1962.

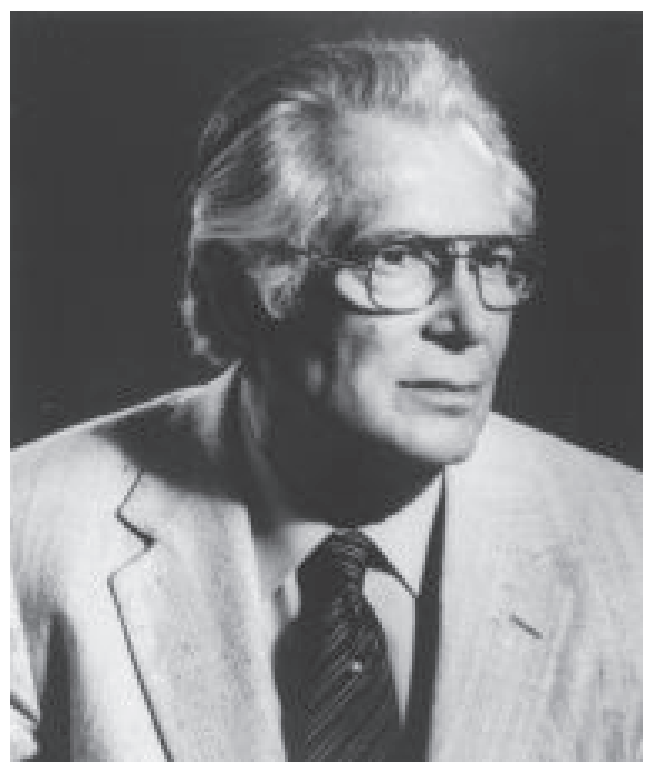

Fig.-3: Robert H. Goetz in 1989
The First Successful Clinical Coronary Artery Bypass Operation:

The world saw the beginning of vascular surgery in early 1950's. It was also the time Goetz came to America and became Associate Professor of Surgery at the Albert Einstein College of Medicine in 1957 and a full Professor and attending surgeon at Bronx Municipality Hospital in 1961. He held both positions until his retirement in $1982 .^{1}$

At that time, it seemed to him that everyone was engaged in searching for methods to improve myocardial blood supply. Their cardioplegia did not guarantee dog's survival, so chose to carry out the operation on the beating heart. At this stage, Dr. Stephen Rosenak, one of his general surgical staff suggested to use Payr'sring and they did it in dogs and patency of anastomosis proved on angiography after six months. ${ }^{11}$

What followed next was the world's first successful clinical coronary artery bypass operation. In his experimental study published in 1960, Goetz described the technique in much detail. When the article was submitted for publication, a coronary mammary anastomosis between the right mammary and right coronary artery using tantalum ring successfully performed on a 38 year old patient, who was a cab driver at Van Etten Hospital, Bronx Municipal Hospital Center, New York, on May 2, 1960. $(\text { Fig } 4)^{1,7}$

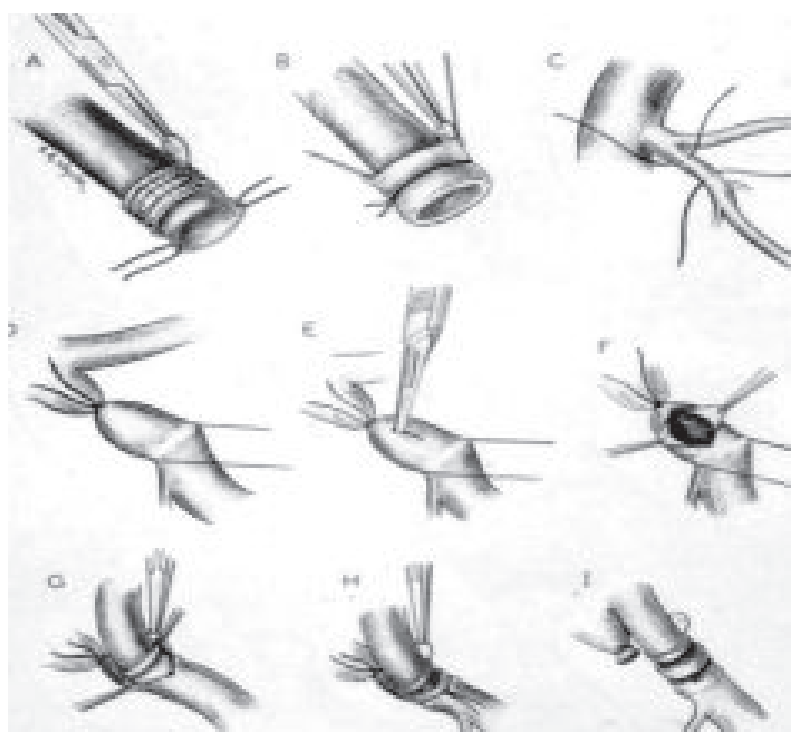

Fig.-4: Technique of nonsuture coronary-mammary anastomosis by Dr, Goetz in May 2, 1960. 
Table-I

The First Clinical Coronary Artery Bypass Operations

\begin{tabular}{|c|c|c|c|c|}
\hline Date & Surgeon & Graft & Technique & Follow-Up \\
\hline May 2, 1960 & Goetz & RITA & Tantalum ring & No angina at 1 year \\
\hline & & & & Pt. died of AMI 1.5 years later \\
\hline April 4, 1962 & Sabiston & SV & Suture & $\begin{array}{l}\text { Pt. died } 3 \text { days later } \\
\text { (This case first reported in 1974) }\end{array}$ \\
\hline Feb 25, 1964 & Kolesov & LITA & Suture & No angina at 3 years follow-up \\
\hline Nov 23, 1964 & $\begin{array}{c}\text { Garrett } \\
\text { Dennis } \\
\text { DeBakey }\end{array}$ & SV & Suture & $\begin{array}{l}\text { No angina at } 7 \text { years follow-up } \\
\text { (This case first reported in 1973) }\end{array}$ \\
\hline March 22, 1967 & Kolesov & LITA & Stapling & No angina at 3 years follow-up \\
\hline May 9, 1967 & Favaloro & SV & Suture & Successful \\
\hline Feb 29, 1968 & Green & LITA & Suture & Successful \\
\hline
\end{tabular}

AMI-acute myocardial infarction,LITA-left internal thoracic artery, RITA-right internal thoracic artery, SV-saphenous vein

Before operation, the patient needed 70 to 90 tablets of nitroglycerine tablets. The operation was carried out through midsternotomy incision. The stented anastomosis was constructed within 17 seconds but it took Dr. Goetz 50 years to arrive to this point. Angiography performed on $14^{\text {th }}$ postoperative day showed the patency of stented anastomosis.

Between May 6, and June 12, 1961, he was treated for recurrent angina pectoris and congestive heart failure at New York Cardiac Home, Yonkers, NY, and discharged with improvement and the cardiologist who examined the patient mentioned that, "the patient had had coronary artery surgery on May 2, 1960, but the exact procedure which was performed can only be guessed." The patient died at Jacobi Hospital, Bronx, NY, on June 23, 1961, of a posterior myocardial infarction. ${ }^{3}$

Ironically, it was not only the first clinical coronary artery bypass of Dr Goetz, but also the only, and the last one. Goetz was far ahead of his time. The introduction of coronary bypass operation created a great deal of anxiety. As it happened with most new procedure like that of me in 2009, when I wanted to operate a case of atrial septal defect closure through RVIAT (Right Vertical Infra-Axillary Thoracotomy) and some of my senior Professors strongly against the procedure. But they congratulated first than the others, when I completed the procedure. I must thank my Professor Dr. Golam Kibria in this regards to support me at that time. But Dr. Goetz could not proceed due not only to violent prohibition of his medical collegue Dr. Jordan but also his chairman who told him to concentrate on vascular surgery and appointed a cardiac surgeon without consulting him. Goetz pioneering work is remarkable, particularly when it is remembered that it took almost 4 years until Kolesov performed a successful coronary artery bypass operation in Russia 7,8 , and 7 years before Favaloro ${ }^{2}$ and 8 years before Green did so in America (Table 1) ${ }^{6}$. In 1962, Sabiston performed an unsuccessful coronary bypass and this case was reported in 1974. In 1964, Garrett, Dennis, and DeBakey performed a successful coronary bypass and did not report this until $1973 .^{5}$

The world was reluctant to accept the new operation even in the end of the 1960s. Favaloro also encountered many difficulties with more conservative colleagues. Resistance was not unique in USA, when Kolesov reported his results in 1967 to the cardiology society of Russia, the society accepted a resolution that "The surgical treatment of coronary artery disease is impossible and has no prospects in the future". Thus Goetz's operation performed in 1960 seemed unthinkable.

\section{Conclusion:}

The coronary bypass operation has evolved from the procedure that "can only be guessed" to one of the most frequently performed operation today. Goetz had a remarkable ability to stay focused on his work. He did what he believed was right, honorable, and of benefit to humanity.

It might be a pleasant surprise for German surgeons to learn that the first coronary bypass operation done by a German. Many American surgeons might be happy to know that it was carried out in America. South Africans might think that they have one more country man of whom to be proud. However, above all, it is gratifying for all of us to see in Goetz a great example of creativity, bravery, and 
integrity, the qualities that every academic surgeon should emulate.

\section{References:}

01. Konstatinov IE. Robert H. Goetz: The Surgeon Who Performed the First Successful Clinical Coronary Artery Bypass Operation. Ann Thorac Surg 2000; 69:1966-1972.

02. Favaloro RG. The challenging dream of heart surgery. Boston: Little Brown, 1994.

03. Olearchyk AS. Coronary revascularization: past, present and future. J Ukr Med Assoc North Am 1988; 35:3-34.

04. Goetz RH. Early surgical research at the University of Cape Town. South African J Surg1988;26:140-147.

05. Garret HE, Dennis EW, DeBakey ME. Aorto-coronary bypass with saphenous vein graft. JAMA 1973;233: 792-794.

06. Green GE, Stertzer SH, Reppert EH. Coronary arterial bypass grafts. Ann Thorac Surg 1968;5:44350.

07. Kolesov VI. Mammary artery-coronary artery anastomosis as method of treatment for angina pectoris. J Thorac Cardiovasc Surg 1967;45: 535-544.

08. Kolesov VI, Potashov LV. Operations on the coronary arteries. Exp Chir Anaesth 1965;10:3-8.

09. Effler DB. Vineberg's operation for myocardial ischemia. Postgrad Med. 1965;37:303-9. 10.Demikhov VP. Experimental transplantation of vital organs. Authorized translation from the Russian by Basil Haigh. New York: Consultant's Bureau, 1962.

11. Goetz RH, Rohman M, Haller JD, Dee R, Rosenak SS. Internal mammary-coronary artery anastomosis. A nonsuture method employing tantalum ring. J Thorac Cardiovasc Surg 1961;41:378-386.

12. Murray G, Hilario J, Porcheron R, Rochlau W. Surgery of coronary heart disease. Angiology 1953;4: 526-4531.

13. Vineberg AM. Development of anastomosis between coronary vessels and transplanted internal mammary artery. Can Med Assoc J 1946;55:117-119.

14. Carrel A. On the experimental surgery of the thoracic aorta and heart. Am J Surg 1910;52:83-187. 